\title{
Desempenho de cultivares de girassol sob diferentes lâminas de irrigação no Vale do Curu, $\mathbf{C E}^{1}$
}

\author{
Performance of cultivars of sunflower under different irrigation levels, in the Vale do \\ Curu, CE
}

\author{
Alexandre Reuber Almeida da Silva ${ }^{2 *}$, Francisco Marcus Lima Bezerra ${ }^{3}$, Carmem Cristina Mareco de Sousa \\ João Valdenor Pereira Filho 5 e Cley Anderson Silva de Freitas ${ }^{5}$
}

\begin{abstract}
Resumo - Com o objetivo de avaliar a influência de seis lâminas de irrigação no desempenho produtivo de duas cultivares de girassol (Catissol 01 e Embrapa 122 V-2000), realizou-se um ensaio na Fazenda Experimental Vale do Curu, no Município de Pentecoste, CE. O delineamento estatístico adotado foi o de blocos ao acaso, no esquema de parcelas subdivididas, com quatro repetições. Nas parcelas, avaliou-se o efeito de seis lâminas de irrigação baseadas em percentuais da evaporação do tanque classe A (ECA), que corresponderam à multiplicação da ECA pelos fatores 0,$25 ; 0,50 ; 0,75 ; 1,00 ; 1,25$ e 1,50 e nas subparcelas, avaliou-se o efeito das duas cultivares. O diâmetro dos capítulos, a massa de 1.000 aquênios, o potencial de produção de aquênios, o teor de óleo dos aquênios e o potencial de produção de óleo foram influenciados significativamente pelas diferentes lâminas de irrigação, sendo que os maiores valores foram obtidos para a cultivar Catissol 01, exceto para o teor de óleo dos aquênios, onde se constatou maiores valores para a cultivar Embrapa 122 V-2000. Houve diferenças significativas entre as cultivares nas variáveis diâmetro de capítulos e potencial de produção de aquênios. A lâmina de irrigação de $533,70 \mathrm{~mm}$ (150\% da ECA) proporcionou os maiores potenciais de produção de aquênios $4.222,76$ e 3.948,02 $\mathrm{kg} \mathrm{ha}^{-1}$, e de óleo $1.851,55$ e 1.760,63 $\mathrm{kg} \mathrm{ha}^{-1}$ para as cultivares Catissol 01 e Embrapa 122 V-2000, respectivamente.
\end{abstract}

Palavras-chave - Helianthus annus. Déficit hídrico. Características agronômicas. Genótipos.

\begin{abstract}
With the objective to value the influence of six levels of irrigation in the agricultural performance of two cultivars of sunflower, (Catissol 01 e Embrapa 122 V-2000), was made an experiment at the Experimental Farm, Valley of Curu River,county of Pentecoste, CE. The experimental design adopted was randomized blocks with divided plots, with four replicates. The effect of six levels of irrigation based on percentage of evaporation of class A pan (ECA) by the factors $0.25 ; 0.50 ; 0.75 ; 1.00 ; 1.25$ and 1.50 , was evaluated for the cultivars. The variables, diameter of head, mass of 1000 achenes, potential of production of achenes, content of oil of the achenes, potential of production of oil,were determined. The greater values were achieved by the cultivar "Catissol 01", except for the content of oil of the achenes, higher for the "Embrapa 122 V-2000". There were significant differences between the cultivars in the variable diameter of head and potential production of achenes. The level of irrigation of $533.70 \mathrm{~mm}(150 \%$ of ECA) proportioned the greater potential production of achenes that was of 4,222.76 and 3,948.02 $\mathrm{kg} \mathrm{ha}^{-1}$, and of oil 1,851.55 and 1,760.63 $\mathrm{kg} \mathrm{ha}^{-1}$ to the cultivars Catissol 01 e Embrapa 122 V-2000, respectively.
\end{abstract}

Key words - Helianthus annus. Water deficit. Agricultural Characteristics. Genotypes.

\footnotetext{
* Autor para correspondência

${ }^{1}$ Recebido para publicação em 27/07/2010; aprovado em 10/11/2010

Pesquisa financiada pelo CNPq

${ }^{2}$ Programa de Pós-Graduação em Engenharia Agrícola, CCA/UFC, Caixa Postal 12.168, Fortaleza-CE, Brasil, 60.455 970, alexandre reuber@hotmail.com ${ }^{3}$ Departamento de Engenharia Agrícola, CCA/UFC, Fortaleza- CE, Brasil, mbezerra@ufc.br

${ }^{4}$ Programa de Pós-Graduação em Engenharia Agrícola/UFRPE, Rua Dom Manoel de Medeiros, s/n, Dois Irmãos, Recife-PE, Brasil, 52.171-900, crismareco@hotmail.com

${ }^{5}$ Programa de Pós-Graduação em Engenharia Agrícola, CCA/UFC, Fortaleza-CE, Brasil, joao_valdenor@hotmail.com, anderson_agrotec@yahoo.com.br
} 


\section{Introdução}

O girassol (Helianthus annus L.) é uma espécie vegetal originária das Américas, pertencente à família Compositae, que possui inúmeras aplicações no mundo contemporâneo e, é considerada uma das plantas das quais se torna possível explorar quase toda a sua totalidade, podendo ser utilizado na alimentação humana, no raçoamento animal e na produção de Biodiesel, além de apresentar aptidão ornamental e importantes propriedades medicinais (DICKMANN et al. 2005; SILVA et al. 2007).

Rússia, Ucrânia, Argentina, China e França são, nesta ordem, os principais produtores mundiais de girassol, tanto em termos de área colhida como na quantidade produzida (FAOSTAT, 2009). O Brasil ainda ocupa uma posição pouco expressiva no que se diz respeito à produção de girassol. Entretanto, é bastante significativo o incremento de áreas destinadas à exploração com esta cultura (BACKES et al., 2008).

A região semiárida do Nordeste brasileiro é comumente afetada por um regime irregular de precipitações, devido à insuficiência e à má distribuição das mesmas ao longo do ano, de tal forma que tais fatos constituem um dos fatores mais limitantes às produtividades agrícolas, comprometendo significativamente o rendimento das culturas. Tais fatos justificam a necessidade de recorrer à prática da irrigação, objetivando amenizar e corrigir os problemas oriundos do suprimento hídrico inadequado na agricultura (GARCIA et al., 2007).

Bilibio et al. (2010) reforçam que na agricultura irrigada deve-se atribuir uma atenção especial ao manejo da irrigação, uma vez que se torna imprescindível conduzir de forma racional a cultura irrigada em condições de campo, determinando de forma precisa as necessidades hídricas da cultura sem déficit, nem excesso, assim como a lâmina e a hora mais adequada para proceder à irrigação visando desta forma maximizar a eficiência do uso da água.

O estudo de diferentes lâminas de irrigação constitui uma maneira bastante prática para se determinar as necessidades hídricas de uma espécie, em certa região para se estimar a quantidade de água que a cultura necessita para crescer e produzir dentro dos limites impostos por seu potencial genético (AZEVEDO; BEZERRA, 2008).

Por isso, as lâminas de irrigação tem sido objeto de estudo de vários pesquisadores nas mais diversas espécies, podendo-se mencionar Azevedo, et al. (2005); Azevedo e Bezerra (2008); Garcia et al. (2007) e Morais et al. (2008).

A literatura tem comprovado que a cultura do girassol responde de maneira significativa à disponibilidade hídrica do solo em decorrência da irrigação, e, dentre eles Acosta (2009) e Silva et al.
(2007) que averiguaram a estreita relação entre irrigação e produtividade nesta cultura.

Conforme Heckler (2002), as diferentes cultivares de uma cultura podem apresentar um comportamento diferenciado, uma em relação à outra, no crescimento, na produtividade e em outras características de interesse agronômico.

Desta forma, estudos entre cultivares e diferentes lâminas de irrigação permitem avaliar o desempenho das culturas, bem como torna possível obter informações acerca de suas necessidades hídricas dentro das especificações edafoclimáticas de cada região, no intuito de aprimorar o manejo da irrigação, aperfeiçoando o rendimento agronômico e financeiro das culturas agrícolas (SILVA et al., 2004).

Diante do exposto, este trabalho foi realizado com o objetivo de avaliar a influência de seis lâminas de irrigação, baseadas em percentuais da evaporação do tanque classe A no desempenho produtivo de duas cultivares de girassol, Catissol 01 e Embrapa 122 V-2000, nas condições edafoclimáticas do Vale do Curu em Pentecoste, CE.

\section{Material e métodos}

O experimento foi conduzido em campo, entre os meses de agosto e novembro de 2008, no Perímetro Irrigado Curu-Pentecoste, na área irrigada AT1, pertencente à Fazenda Experimental Vale do Curu FEVC, da Universidade Federal do Ceará - UFC, no Município de Pentecoste - CE, em um Neossolo Flúvico, textura franco arenosa. O clima da região, segundo a classificação de Köppen, é BSw’h', isto é, semiárido com chuvas irregulares, com duas estações climáticas bem definidas, com precipitação anual de $800,9 \mathrm{~mm}$, temperatura média anual de $27,1{ }^{\circ} \mathrm{C}$ e umidade relativa média do ar de 74\% (EMBRAPA, 2001).

A área total ocupada pelo experimento foi de $810 \mathrm{~m}^{2}$, composta por 96 linhas de plantas. Cada linha útil de plantas ocupou uma área de $4,5 \mathrm{~m}^{2}$, que continha 20 plantas. $\mathrm{O}$ experimento obedeceu ao delineamento estatístico de blocos ao acaso em parcelas subdivididas, com seis tratamentos na parcela e dois nas subparcelas, com quatro repetições.

Nas parcelas, avaliou-se o efeito de seis lâminas de irrigação baseadas na evaporação do tanque classe A (ECA), e nas subparcelas, as duas cultivares. As lâminas de irrigação corresponderam à: $\mathrm{L} 1$, lâmina de irrigação referente a $25 \%$ da ECA; L2 - 50\% da ECA; L3 - 75\% da ECA; L4 - 100\% da ECA; L5 - 125\% da ECA e L6 - 150\% da ECA. Como tratamentos secundários foram utilizados duas cultivares de girassol, Catissol 01 e Embrapa 122 V-2000. 
As vinte e quatro parcelas mediram $2,7 \mathrm{~m}$ de largura por $6 \mathrm{~m}$ de comprimento e continham 96 plantas cada. As subparcelas, quarenta e oito no total, mediam 3,6 m de largura e $3 \mathrm{~m}$ de comprimento, composta de duas linhas úteis entre duas linhas de bordaduras no mesmo espaçamento do experimento, de modo a evitar influência entre os tratamentos, e continham 48 plantas cada.

A área do experimento foi preparada com aração, gradagem cruzada e aberturas de sulcos espaçados de 0,9 m. As cultivares foram semeadas manualmente em 7 de agosto de 2008 no espaçamento entre linhas de $0,9 \mathrm{~m}$, em covas abertas sobre os sulcos já fechados, com uma média de quatro sementes por cova, espaçadas de $0,25 \mathrm{~m}$ na linha. Ao $7^{\circ}$ dia após a semeadura em 14 de agosto de 2008, observou-se uma germinação de $100 \%$. No desbaste, realizado manualmente as plantas foram arrancadas rente ao solo, deixando-se apenas uma planta por cova.

O experimento foi irrigado por um sistema irrigação por gotejamento. Os gotejadores eram do tipo autocompensantes, com vazão média de $3,75 \mathrm{~L} \mathrm{~h}^{-1}$ a uma pressão de serviço de $150 \mathrm{kPa}$, espaçados de $0,5 \mathrm{~m}$ na linha com um gotejador por duas plantas.

Até o $28^{\circ}$ dia após a semeadura, todos os tratamentos receberam a mesma lâmina de irrigação, objetivando estabelecer uma uniformidade no estande. As irrigações foram feitas com intervalo de dois dias e o tempo de irrigação de 2 horas, sendo aplicada uma lâmina média de 8,4 mm, que correspondeu à lâmina equivalente a $100 \%$ da evaporação no tanque classe $\mathrm{A}$, naquele período. Após o $28^{\circ}$ dia após a semeadura, as lâminas de irrigação passaram a ser aplicadas de acordo com os tratamentos.

Durante o ciclo da cultura foram realizadas duas capinas, com intuito de eliminar as ervas daninhas.
Foram procedidos também, os tratamentos fitossanitários necessários, ao aparecerem os primeiros sintomas de pragas e doenças. A colheita foi efetuada manualmente aos 105 dias após a semeadura.

As variáveis agronômicas avaliadas das plantas enquadradas na área útil do experimento em cada repetição e para cada tratamento foram variáveis de: produtividade (diâmetro dos capítulos, massa de 1.000 aquênios, potencial de produção de aquênios, teor de óleo dos aquênios e potencial de produção de óleo).

Os dados das variáveis avaliadas foram submetidos à análise de variância pelo teste $\mathrm{F}$ a 1 e $5 \%$ de probabilidade. Quando verificado efeito significativo na análise de variância, os dados obtidos nos diferentes tratamentos de natureza qualitativa foram comparadas através do teste de Tukey em nível de 1 e $5 \%$ de probabilidade e os de natureza quantitativa, foram submetidos ao estudo de regressão, buscando-se ajustar equações com significados biológicos, sendo selecionado os modelos matemáticos que apresentaram melhores níveis de significância e maior valor de coeficiente de determinação $\left(\mathrm{R}^{2}\right)$, utilizandose para isso o software para análises estatísticas da Universidade Federal de Viçosa (2005) SAEG 9.0 UFV.

\section{Resultados e discussão}

De acordo com o resumo da análise da variância (TAB. 1), verifica-se que ocorreu efeito significativo $(\mathrm{P}<0,01)$ das diferentes lâminas de irrigação sobre as variáveis diâmetro dos capítulos, massa de 1.000 aquênios, potencial de produção de aquênios, teor de óleo dos aquênios e potencial de produção de óleo. No

Tabela 1 - Resumo da análise de variância para os dados de diâmetro dos capítulos (DCAP), massa de 1000 aquênios (M1000A), potencial de produção de aquênios (PPA), teor de óleo dos aquênios (TOA) e potencial de produção de óleo (PPO). FEVC, Pentecoste, CE, $2008^{1}$

\begin{tabular}{|c|c|c|c|c|c|c|}
\hline \multirow[b]{2}{*}{ Fontes de variação } & \multirow[b]{2}{*}{ GL } & \multicolumn{5}{|c|}{ Valores de F } \\
\hline & & DCAP & M1000A & PPA & TOA & PPO \\
\hline Total & 47 & - & - & - & - & - \\
\hline Bloco & 3 & $2,84 \mathrm{~ns}$ & $0,36 \mathrm{~ns}$ & $10,33 * *$ & $23,51 * *$ & $8,51 * *$ \\
\hline Água (A) & 5 & $22,94 * *$ & $12,11 * *$ & $84,48 * *$ & $24,15 * *$ & $72,53 * *$ \\
\hline Resíduo (A) & 15 & - & - & - & - & - \\
\hline Cultivar (C) & 1 & $20,03 * *$ & $1,25 \mathrm{~ns}$ & $15,01 * *$ & $2,30 \mathrm{~ns}$ & $2,19 \mathrm{~ns}$ \\
\hline Interação (A x C) & 5 & $1,13 \mathrm{~ns}$ & $0,38 \mathrm{~ns}$ & $0,94 \mathrm{~ns}$ & $0,41 \mathrm{~ns}$ & $0,17 \mathrm{~ns}$ \\
\hline Resíduo (B) & 18 & - & - & - & - & - \\
\hline C.V. & & 5,23 & 6,34 & 7,99 & 8,33 & 12,74 \\
\hline
\end{tabular}

**Nível de significância a 1\%; ns: não significante; C.V. coeficiente de variação (\%) 
entanto, foi observado efeito significativo das cultivares apenas nas variáveis diâmetro dos capítulos e potencial de produção de aquênios. Não foram detectadas diferenças significativas na interação lâminas de irrigação $\mathrm{x}$ cultivares nas variáveis analisadas. Os diâmetros dos capítulos diferiram estatisticamente entre as cultivares, tendo a Catissol 01 alcançado maiores valores $(18,06 \mathrm{~cm})$ quando comparada à cultivar Embrapa 122 - V2000 (16,88 cm) (TAB. 2).

Tabela 2 - Valores médios do diâmetro do capítulo (DCAP), em $\mathrm{cm}$, e do potencial de produção de aquênios (PPA), em $\mathrm{kg} \mathrm{ha}^{-1}$, das cultivares Catissol 01 e Embrapa $122 \mathrm{~V}-2000$. FEVC, Pentecoste, CE, $2008^{1}$

\begin{tabular}{crc}
\hline \multirow{2}{*}{ Variáveis } & \multicolumn{2}{c}{ Valores médios $^{1}$} \\
\cline { 2 - 3 } & Catissol 01 & Embrapa 122 - V2000 \\
\hline DCAP & $18,06 \mathrm{a}$ & $16,88 \mathrm{~b}$ \\
PPA & $3468,35 \mathrm{a}$ & $3162,98 \mathrm{~b}$ \\
\hline
\end{tabular}

${ }^{1}$ Médias seguidas pela mesma letra dentro de cada linha não diferem entre si pelo teste de Tukey a 5\% de probabilidade

As cultivares responderam de forma semelhante quanto ao incremento no diâmetro do capítulo em função das crescentes lâminas de irrigação. Constatou-se para esta variável, por meio da análise de regressão, que o modelo matemático que melhor se ajustou aos dados para as cultivares foi do tipo linear, com efeito significativo $(\mathrm{P}<0,01)$ e coeficientes de determinação de 0,889 e 0,901 para a Catissol 01 e Embrapa 122 V2000, respectivamente (FIG. 1a).

Silva et al. (2007) observaram aumento relativo linear no diâmetro dos capítulos em função da lâmina de água aplicada e o maior diâmetro dos capítulos de girassol $(17,95 \mathrm{~cm})$ foi proporcionado com a aplicação da lâmina de 522,14 mm, bastante similar à máxima lâmina de irrigação aplicada no presente trabalho. Corroborando com o presente trabalho, Gomes, Ungaro e Vieira (2003) também constataram que os tratamentos submetidos à deficiência hídrica exibem capítulos de menores diâmetros.

Lobo e Grassi Filho (2007) relatam que o diâmetro de capítulo é um componente de produção de grande importância na comparação de cultivares de girassol, por apresentar associação positiva com a produtividade de grãos, e ainda segundo Amorin et al. (2008) para assegurar elevadas produtividades torna-se necessário eleger genótipos que possuem capítulos de maiores diâmetros, em decorrência da positiva correlação que existe entre esta variável e a produtividade.
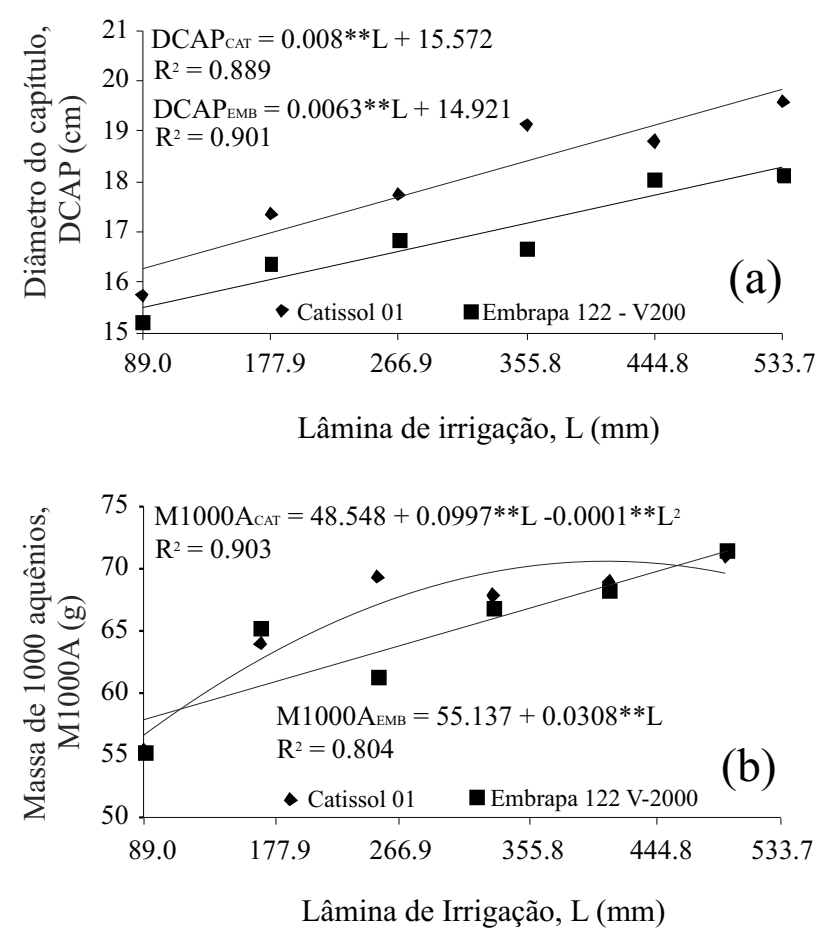

Figura 1 - Análise de regressão para estimativa do diâmetro de capítulos (a) e da massa de 1000 aquênios (b) do girassol, cultivares Catissol 01 e Embrapa 122 V-2000 submetidas a diferentes lâminas de irrigação. FEVC, Pentecoste, CE, 2008

Resultados semelhantes aos obtidos com o diâmetro do capítulo foram também constatados por Mello et al. (2006) que encontraram médias situadas no intervalo de 14,4 a 16,6 cm e por Lira et al. (2010) que encontraram valores médios variando de 14,0 a $20,0 \mathrm{~cm}$.

Ao analisar o efeito das diferentes lâminas de irrigação sobre a massa de 1.000 aquênios das cultivares através da análise de regressão (FIG. 1b) verifica-se que o modelo polinomial de segundo grau foi o que melhor se ajustou aos dados para a Catissol 01 , com efeito significativo $(\mathrm{P}<0,01)$ e coeficiente de determinação de 0,903. Para a Embrapa 122 V-2000, verifica-se que o modelo linear foi o que melhor se ajustou aos dados com efeito significativo $(\mathrm{P}<0,01)$ e coeficiente de determinação de 0,804 .

A partir da análise de regressão verificou-se que a massa de 1000 aquênios atingiu um valor máximo $(73,39 \mathrm{~g})$ na lâmina de irrigação equivalente a 498,5 mm (140,10\% da ECA) para a cultivar Catissol 01. Já para a 
cultivar Embrapa 122 V-2000, a massa de 1.000 aquênios aumentou linearmente com as lâminas aplicadas, atingindo um valor máximo de $71,49 \mathrm{~g}$ na lâmina de irrigação correspondente a $150 \%$ da ECA $(533,7 \mathrm{~mm})$. Os valores de massa de 1.000 aquênios, alcançados no presente trabalho, foram superiores aos encontrados por Silva et al. (2007), trabalhando com outras cultivares de girassol independente da cultivar e da lâmina aplicada. Castro et al. (2006), em ensaio com a cultura do girassol (híbrido Morgan 738) no município de Piracicaba, São Paulo também averiguaram que o estresse hídrico cooperou para a redução da massa dos aquênios.

Braz e Rossetto (2009) avaliaram a massa de 1.000 aquênios em três lotes de aquênios da cultivar Embrapa 122 V-2000 e constataram que as mesmas atingiram uma média de 53,66 g, valor este inferior ao encontrado neste trabalho para esta cultivar. Amorin et al. (2008) também mensuraram esta variável e constataram que as cultivares Catissol 01 e Embrapa 122 V-2000 atingiram uma média de 38 e $39 \mathrm{~g}$, respectivamente, e não evidenciaram diferenças significativas no teste de médias entre estas duas cultivares. Gomes, Ungaro e Vieira (2003) trabalhando com a cultivar M 742 no município de Limeira, Estado de São Paulo, constataram que a produção de aquênios aumentou conforme diminuiu o déficit hídrico.

Com relação ao potencial de produção de aquênios, observa-se que houve diferença significativa entre as duas cultivares, ao nível de significância de $5 \%$ e que os maiores valores do potencial de produção de aquênios foram obtidos pela cultivar Catissol 01 (TAB. 2).

Verificou-se ainda que os resultados alcançados são condizentes com os obtidos por Martins, Lessa e Pitombeira (2008) quando constataram, também, diferença significativa entre os genótipos estudados sob regime de irrigação no município de Pentecoste, CE. De acordo com os autores, a cultivar Embrapa 122 V-2000 apresentou uma produtividade média de $1.825,00 \mathrm{~kg} \mathrm{ha}^{-1}$, valor este inferior em $116,32 \%$ ao potencial de produção média de aquênios desta mesma cultivar obtido com a aplicação da máxima lâmina de irrigação neste ensaio (3.948,02 $\left.\mathrm{kg} \mathrm{ha}^{-1}\right)$. Provavelmente, esta diferença é decorrente da ausência de manejo da irrigação durante a execução do experimento destes autores, já que as irrigações eram realizadas sem controle de vazão via superfície. Fatos que provavelmente podem ter exposto a cultura a uma situação de estresse por déficit ou excesso hídrico conforme também constatou Baldo et al., (2009) ao avaliar o comportamento do algodoeiro sob estresse hídrico, demonstrando que tal condição impossibilitou a manifestação de todo o potencial produtivo da cultivar.
Acosta (2009) trabalhando com a cultivar Catissol 01 , evidenciou que a lâmina total de irrigação aplicada de $626,4 \mathrm{~mm}$ por aspersão convencional acarretou uma produtividade de grãos de $2.260 \mathrm{~kg} \mathrm{ha}{ }^{-1}$. Observa-se, portanto que a lâmina de irrigação deste trabalho é superior à máxima lâmina aplicada neste experimento em $92,7 \mathrm{~mm}$ e que acarretou uma produção de $1.962,16 \mathrm{~kg} \mathrm{ha}^{-1}$ de aquênios a menos que este estudo, o que gera uma diferença de em termos percentuais de $86,84 \%$ de incrementos de produtividade ao se comparar os potenciais produtivos.

Estudos desenvolvidos por Oliveira et al. (2008) com objetivo de conhecer o comportamento produtivo de cultivares de girassol em diferentes áreas do Nordeste brasileiro também evidenciaram diferenças significativas entre as cultivares, com médias de produtividade variando de 1.996 a $2.623 \mathrm{~kg} \mathrm{ha}^{-1}$, valores estes inferiores as médias gerais dos potenciais produtivos obtidos neste ensaio para ambas cultivares.

Ao analisar o efeito das lâminas de irrigação sobre o potencial de produção de aquênios por meio da análise de regressão (FIG. 2a), constatou-se que o modelo matemático que melhor se ajustou aos dados para ambas cultivares foi do tipo linear, com efeito significativo $(\mathrm{P}<0,01)$ e coeficiente de determinação de 0,951 e 0,841, para as cultivares Catissol 01 e Embrapa 122 V-2000, respectivamente. Para a lâmina de irrigação referente a $150 \%$ da ECA $(533,7 \mathrm{~mm})$ o potencial produtivo alcançou $4.222,76$ e $3.948,02 \mathrm{~kg} \mathrm{ha}^{-1}$ para as cultivares Catissol e Embrapa 122, respectivamente (FIG. 2a).

Azevedo e Bezerra (2008) avaliaram os efeitos de diferentes lâminas de irrigação na cultura da bananeira e também constataram que o modelo que melhor se ajustou aos dados para a variável produtividade foi do tipo linear. É provável que as informações fornecidas por estes autores sirvam para melhor explicar este comportamento da cultivar Embrapa $122 \mathrm{~V}-2000$, pois para eles este comportamento é no mínimo curioso em se tratando de um ensaio biológico que corriqueiramente deve alcançar um ponto de máximo, e eles atribuem, este fato dentre outros fatores, à grande exigência de água pela cultura e à classificação textural do solo que assim como a do presente experimento, também é franco-arenosa, e dentre suas características, se destaca por possuir baixa capacidade de retenção de água.

Ainda corroborando com os presentes resultados, Nobre et al. (2010) avaliaram a produção do girassol cv. Embrapa 122 V-2000 sob irrigação com efluente doméstico e averiguaram que a reposição da necessidade hídrica mediante balanço hídrico favoreceu a elevação da produtividade, sendo que os maiores incrementos foram observados com reposição de $120 \%$. 

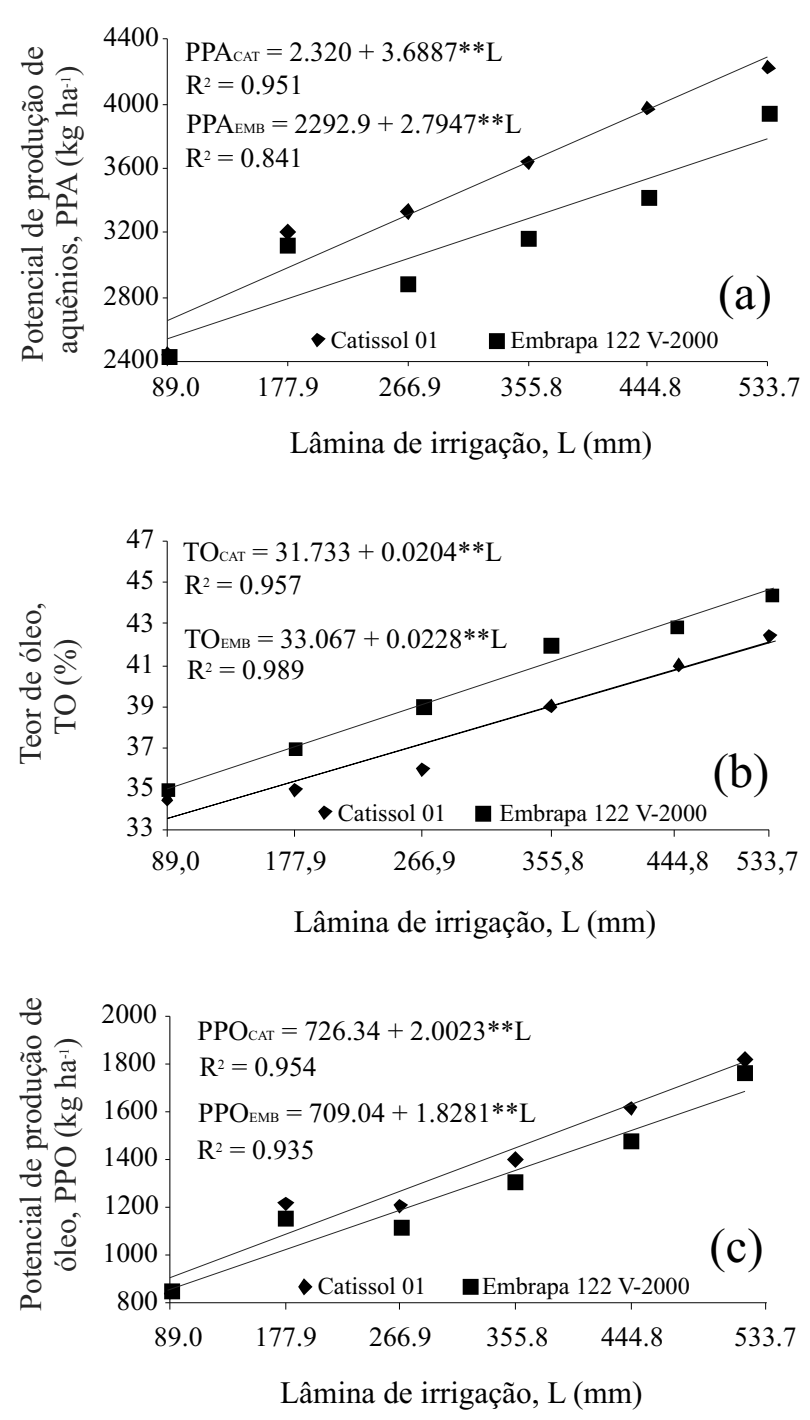

Figura 2 - Análise de regressão para estimativa do potencial de produção de aquênios (a), do teor de óleo (b) e do potencial de produção de óleo (c) do girassol, cultivares Catissol 01 e Embrapa 122 V-2000. FEVC, Pentecoste, CE, 2008

Fazendo uma analogia entre as variáveis analisadas, observa-se que a massa de 1.000 aquênios da cultivar Catissol 01 se apresentou ligeiramente superior quando comparada com a cultivar Embrapa 122 V-2000, e o potencial produtivo desta cultivar foi também superior à cultivar Embrapa 122 V-2000, evidenciando que o fato de possuir aquênios de massa superior é determinante para se ter melhor produtividades nos distintos materiais genéticos desta cultura. Observa-se ainda, que a produtividade de aquênios e o diâmetro de capítulo têm uma relação direta, pois a maior produtividade foi obtida justamente com a cultivar Catissol 01 que exibiu capítulos de maiores diâmetros, reforçando a associação positiva entre o diâmetro do capítulo e a produtividade de aquênios.
Tais observações também estão condizentes com resultados obtidos por Amorin et al. (2008) ao relatarem que existem correlações significativas entre a produtividade de aquênios e as características diâmetro do capítulo e massa de mil aquênios. Para estes autores, tais componentes de produção apresentaram um efeito direto positivo sobre a produtividade de aquênios.

De acordo com Thomaz (2008), a cultura do girassol se comporta de maneira significativa à reposição de água no solo por meio da prática da irrigação, respondendo positivamente com incrementos na produtividade. $\mathrm{O}$ autor afirma ainda, que em situações de limitada disponibilidade hídrica a produção de grãos é comprometida.

É provável que as afirmações de Cechin et al. (2010) sirvam para melhor explicar o fato de se constar menores potenciais de produção de aquênios naqueles tratamentos submetidos às aplicações das menores lâminas de irrigação em ambas cultivares, uma vez que estes autores relatam que em condições de deficiência hídrica as plantas se utilizam do mecanismo de fechamento dos estômatos no intuito de restringir a perda de água, reduzindo a transpiração, sacrificando a absorção de $\mathrm{CO}_{2}$, acarretando como consequência reduções nas taxas fotossintéticas, fatos que reduzem a acumulação de fotossintatos e por conseguinte a produtividade de aquênios nesta cultura.

Para o teor de óleo dos aquênios, em função de lâminas crescentes de irrigação da cultivar Catissol 01 através de análise de regressão (FIG. 2b), constatou-se que o comportamento dos dados foram crescentes e o modelo que melhor se ajustou aos dados foi do tipo linear com efeitos significativos $(\mathrm{P}<0,01)$ e coeficiente de determinação de 0,957. E ao se analisar o efeito das lâminas de água sobre o teor de óleo dos aquênios da cultivar de girassol Embrapa 122 V-2000, através de análise de regressão, constatou-se também que o modelo que melhor se ajustou aos dados foi do tipo linear, com efeitos significativos $(\mathrm{P}<0,01)$ e coeficiente de determinação de 0,989 .

Pela Figura $2 b$ verificou-se que, na medida em que a lâmina de irrigação disponibilizada para a cultura decresceu, ocorreram decréscimos na porcentagem de óleo dos aquênios. Observou-se que o teor de óleo dos aquênios da cultivar Embrapa 122 V-2000 se apresentou ligeiramente superior (45\%) quando comparada à cultivar Catissol 01 (43\%), entretanto cabe ressaltar que não se constatou diferença significativa quando comparando às duas cultivares. Cabe ressaltar que o maior teor de óleo neste ensaio não foi obtido na cultivar que apresentou maior potencial para a produção de aquênios, já que se observa uma maior curva de resposta para a cultivar Embrapa 122 V-2000, o que evidencia a independência destes fatores de produção no girassol. 
Ivanoff et al. (2008) objetivando avaliar o teor de óleo de cultivares de girassol na região Norte do Brasil constatou que a cultivar Embrapa 122-V2000 apresentou um percentual de $47,15 \%$ de óleo, se aproximando bastante dos presentes resultados.

A partir da análise de regressão do potencial de produção de óleo em função das lâminas de irrigação (FIG. 2c), constatou-se que o modelo matemático que melhor se ajustou aos dados foi do tipo linear em ambas cultivares comefeitos significativos $(\mathrm{P}<0,01)$ e coeficiente de determinação de 0,954 e 0,935, para as cultivares Catissol 01 e Embrapa 122 V-2000, respectivamente. Verificou-se ainda que a lâmina de 533,70 mm (150\% da ECA) é potencialmente capaz de produzir 1.851,55 e $1.760,63 \mathrm{~kg} \mathrm{ha}^{-1}$ de óleo, para as cultivares Catissol $01 \mathrm{e}$ Embrapa 122-V2000, respectivamente.

Ivanoff (2008) alcançou como resultado um potencial de produção de óleo de $779,16 \mathrm{~kg} \mathrm{ha}^{-1}$ para a cultivar Embrapa 122-V2000, valor inferior ao alcançado neste trabalho. Com relação aos dados de potencial de produção de óleo para a cultivar Catissol 01, observou-se que independente da lâmina de irrigação que foi aplicada os valores obtidos foram superiores aos estimados por Thomaz (2008), que constatou em média $516 \mathrm{~kg} \mathrm{ha}^{-1}$ de óleo.

É provável, que as afirmações de Gomes (2005) sirvam para melhor explicar o fato de se constatar menores potenciais de produção de óleo nos tratamentos submetidos às aplicações das menores lâminas de irrigação, uma vez que em condições de deficiência hídrica as plantas se encontram em uma situação crítica no que se relaciona ao balanço energético e para elas é mais oportuno investir na produção de compostos protéicos em detrimento à produção de óleo, justamente pelo menor dispêndio em energia exigido pela produção de proteína, já que a síntese de óleo se dá por meio dos produtos obtidos na degradação da glicose e exige, portanto, maior consumo energético.

\section{Conclusões}

1. O diâmetro de capítulos, a massa de 1.000 aquênios, o potencial de produção de aquênios, o teor de óleo dos aquênios e o potencial de produção de óleo foram influenciadas significativamente pelas diferentes lâminas de irrigação;

2. As cultivares exibiram um comportamento significativamente diferenciado nos parâmetros diâmetro de capítulos e potencial de produção de aquênios;

3. A máxima lâmina de irrigação de $533,70 \mathrm{~mm}$ (150\% da ECA) proporcionou os maiores potenciais de produção de aquênios, que foram de $4.222,76$ e $3.948,02 \mathrm{~kg} \mathrm{ha}^{-1}$, e de óleo $1.851,55$ e $1.760,63 \mathrm{~kg} \mathrm{ha}^{-1}$ para as cultivares Catissol 01 e Embrapa 122 V-2000, respectivamente nas condições edafoclimáticas do Vale do Curu, no Município de Pentecoste, CE;

4. A cultivar Catissol 01, apresentou um melhor desempenho produtivo, exceto para o teor de óleo dos aquênios, onde se constatou maiores valores para a Embrapa 122 V-2000.

\section{Agradecimentos}

Os autores agradecem ao $\mathrm{CNPq}$ pelo suporte financeiro dado a esta pesquisa e pelas bolsas concedidas aos autores.

\section{Referências}

ACOSTA, J. F. Consumo hídrico da cultura do girassol irrigada na região da Chapada do Apodi - RN. 2009. 56f. Dissertação (Mestrado em Meteorologia) - Universidade Federal de Campina Grande, Campina Grande.

AMORIN, E. P. et al. Correlações e análise de trilha em girassol. Bragantia, v. 67, n. 02, p. 307-316, 2008.

AZEVEDO, B. M. de et al. Rendimento da pimenteira em função de lâminas de irrigação. Revista Ciência Agronômica, v. 36, n. 03 , p. $268-273,2005$.

AZEVEDO, J. H. O. de; BEZERRA, F. M. L. Resposta de dois cultivares de bananeira a diferentes lâminas de irrigação. Revista Ciência Agronômica, v. 39, n. 01, p. 28 - 33, 2008.

BACKES, R. L. et al. Desempenho de cultivares de girassol em duas épocas de plantio de safrinha no Planalto Norte Catarinense. Scientia Agraria, v. 09, n. 01, p. 41-48, 2008.

BALDO, R. et al. Comportamento do algodoeiro cultivar delta opal sob estresse hídrico com e sem aplicação de bioestimulante. Ciência e Agrotecnologia, v. 33, n. spe, pp. 1804-1812, 2009.

BILIBIO, C. et al. Desenvolvimento vegetativo e produtivo da berinjela submetida a diferentes tensões de água no solo. Revista Brasileira de Engenharia Agrícola e Ambiental, v. 14, n. 07, p. 730-735, 2010.

BRAZ, M. R. S.; ROSSETTO, C. A. V. Estabelecimento de plântulas e desempenho de plantas em resposta ao vigor dos aquênios de girassol. Ciência Rural, v. 39, n. 07, 2009.

CASTRO, C. de; MOREIRA, A.; OLIVEIRA, R. F. de; DECHEN, A. R. Boro e estresse hídrico na produção do girassol. Ciência e Agrotecnologia, v. 30, n. 02, p. 214-220, 2006.

CECHIN, I. et al. Respostas diferenciais entre as folhas jovens e adultas de plantas de girassol para o estresse oxidativo causado pelo déficit hídrico. Ciência Rural, v. 40, n. 06, p. 1290-1294, 2010. 
DICKMANN, L. et al. Comportamento de sementes de girassol (Helianthus annuus L.) submetidas a estresse salino. Revista de Ciências Agro-Ambientais, v. 03, p. 64-75, 2005.

EMBRAPA. Centro Nacional de Pesquisa de Agroindústria Tropical. Dados climatológicos: Estação de Pentecoste, 2000; Fortaleza: Embrapa Agroindústria Tropical/UFC, 2001. 14 p.

FAOSTAT Statistical Databases. FAO, 2009. Disponível em: $<$ http: //faostat.fao.org.>. Acesso em: 28 ago. 2009.

GARCIA, F. C. de H.; BEZERRA, F. M. L; FREITAS, C. A. S. de. Níveis de irrigação no comportamento produtivo do mamoeiro Formosa na Chapada do Apodi, CE. Revista Ciência Agronômica, v. 38, n. 02, p. 136-141, 2007.

GOMES, E. M.; UNGARO, M. R. G.; VIEIRA, D. B. Influência da suplementação hídrica na altura de planta, diâmetro de capítulo, peso de sementes e produção de grãos. In: SIMPÓSIO NACIONAL DE GIRASSOL, 3.; REUNIÃO NACIONAL DA CULTURA DE GIRASSOL, 15., 2003, Minas Gerais. Anais... Ribeirão Preto: CATI, 2003. (CD-ROM).

GOMES, E. M. Parâmetros básicos para a irrigação sistemática do girassol (Helianthus annus L.). 2005. 99 f. Tese (Doutorado em Engenharia Civil) - Faculdade de Engenharia Civil, Arquitetura e Urbanismo, Universidade Estadual de Campinas, Campinas, 2005.

HECKLER, J. C. Sorgo e girassol no outono-inverno, em sistema plantio direto, no Mato Grosso do Sul, Brasil. Ciência Rural, v. 32, n. 03, p. 517-520, 2002.

IVANOFF, M. E. et al. Teor de óleo e produtividade de girassol de diferentes cultivares submetidas a cinco doses de potássio. In: CONGRESSO BRASILEIRO DE BIOCOMBUSTÍVEIS E BIOENERGIA; SIMPÓSIO NACIONAL DE BIOCOMBUSTÍVEIS, 2008, Uberlândia. Anais... Uberlândia: Sociedade Brasileira de Biocombustíveis e Bioenergia, 2008. (CD- ROM).

LIRA, M. A. et al. Desempenho de cultivares de girassol (helianthus annuus. L.) no estado do Rio Grande do Norte. In: CONGRESSO BRASILEIRO DE MAMONA, 4.; SIMPÓSIO INTERNACIONAL DE OLEAGINOSAS ENERGÉTICAS, 1., João Pessoa. Anais... Campina Grande: Embrapa Algodão, 2010. p. 1700-1703.
LOBO, T. F.; GRASSI FILHO, H. Níveis de lodo de esgoto na produtividade do girassol. Revista Ciencia del Suelo e Nutricíon Vegetal, v. 07, n. 03, p. 16-25, 2007.

MARTINS, Y. R. C.; LESSA, T. N. U.; PITOMBEIRA, J. B. Competição de genótipos de girassol sob condições de irrigação. In: CONGRESSO BRASILEIRO DE BIOCOMBUSTÍVEIS E BIOENERGIA; SIMPÓSIO NACIONAL DE BIOCOMBUSTÍVEIS, 2008, Uberlândia. Anais... Uberlândia: Sociedade Brasileira de Biocombustíveis e Bioenergia, 2008. (CD- ROM).

MELLO, R. et al. Características fenológicas, produtivas e qualitativas de híbridos de girassol em diferentes épocas de semeadura para produção de silagem. Revista Brasileira de Zootecnia, v. 35, n. 03, p. 672-682, 2006.

MORAIS, N. B. de et al. Resposta de plantas de melancia cultivadas sob diferentes níveis de água e de nitrogênio. Revista Ciência Agronômica, v. 39, n. 03, p.369-377, 2008.

NOBRE, R. G. et al. Produção do girassol sob diferentes lâminas com efluentes domésticos e adubação orgânica. Revista Brasileira de Engenharia Agrícola e Ambiental, v. 14, n. 07, p. 747-754, 2010.

OLIVEIRA, I. R.etal. Comportamento de Cultivares de Girassol no Agreste e Tabuleiros Costeiros do Nordeste Brasileiro na Safra de 2007. In: CONGRESSO BRASILEIRO DE AGROBIENERGIA; SIMPÓSIO INTERNACIONAL DE BIOCOMBUSTÍVEIS, 2008, Uberlândia. Anais... Uberlândia: Sociedade Brasileira de Biocombustíveis e Bioenergia, 2008. (CD- ROM).

SILVA, L. B. et al. Comportamento vegetativo de cultivares de banana sob diferentes lâminas de irrigação. Pesquisa Agropecuária Tropical, v. 34, n. 02, p. 93-98, 2004.

SILVA, M. L. O. et al. Crescimento e produtividade do girassol cultivado na entressafra com diferentes lâminas de água. Revista Brasileira de Engenharia Agrícola e Ambiental, v. 11, n. 05, p. 482-488, 2007.

THOMAZ, G. L. Comportamento de cultivares de girassol em função da época de semeadura na região de Ponta Grossa, PR. 2008. 92f. Dissertação (Mestrado em Fitotecnia) - Universidade Estadual de Ponta Grossa, Ponta Grossa.

UNIVERSIDADE FEDERAL DE VIÇOSA. Sistema de análises estatísticas e genéticas - SAEG 9.0, Viçosa: UFV, 2005. 